\title{
Contamination of Paddy Soil and Rice with Arsenic
}

\author{
Khageshwar Singh Patel1, Bharat Lal Sahu1, Shobhana Ramteke1, Elza Bontempi2 \\ ${ }^{1}$ School of Studies in Chemistry/Environmental Science, Pt. Ravishankar Shukla University, Raipur, India \\ ${ }^{2}$ INSTM and Chemistry for Technologies Laboratory, University of Brescia, Brescia, Italy \\ Email: patelks_55@hotmail.com
}

Received 22 January 2016; accepted 15 April 2016; published 18 April 2016

Copyright (C) 2016 by authors and Scientific Research Publishing Inc.

This work is licensed under the Creative Commons Attribution International License (CC BY). http://creativecommons.org/licenses/by/4.0/

(c) (i) Open Access

\begin{abstract}
The drinking water and food are main pathway entry of the As in humans and animals. Their intakes cause diseases i.e. skin cancer, vascular disorder, etc. A wide variety of the rice is cultivated in the central India. The field soil and rice cultivated in the summer season at Koudikasa village, central India were selected for the As contamination studies. The concentration (n $=20)$ of totalAs (AsT) in the field soil, rice grain, husk, straw and root was ranged from $44-270,0.17-0.72$, $0.40-1.58,2.5-5.9$ and $204-354 \mathrm{mg} / \mathrm{kg}$ with mean value of $126 \pm 28,0.47 \pm 0.07,0.83 \pm 0.15,4.2$ \pm 0.5 and $276 \pm 21 \mathrm{mg} / \mathrm{kg}$, respectively. The total arsenic, monomethylarsenonate, dimethylarsinite and inorganic $A s$ in the rice grain are quantified.
\end{abstract}

\section{Keywords}

Arsenic, Soil, Rice, Accumulation, Speciation

\section{Introduction}

Arsenic is a toxic metalloid, and its long exposure causes diseases i.e. hypopigmentation, melanosis, keratosis, skin, bladder, lung, and prostate cancer, etc. [1]. Rice is a predominant staple food in many countries i.e. Asia, Pacific, America and Africa. The rice husk and straw are used as fodder for feeding cattle and fuel. The exposure of arsenic from rice has been reported a global health issue [2]-[4]. The elevated levels of As in the field soils in various regions of the World were reported [5]-[12]. Arsenic is a bioactive toxic element, accumulated in rice of several regions of the World [13]-[19]. In the present work, the contamination of As in the paddy soil, rice grain, husk, straw and root grown in the contaminated environment, Kaudikasa village, Ambagarh Chowki, central India is described. The speciation and translocation of As in various parts of the rice plants are discussed. 


\section{Methods and Materials}

\subsection{Choice of Study Area}

The Ambagarh Chowki block, Rajnandgaon district, Chhattisgarh state, India is a hot spot for the As contamination research due to the huge mineralization of As in the environment [20] [21]. The studied area falls in a tribal belt with population of $\approx 0.1$ million over 155 villages. Among them, Koudikasa village (area $\approx 5 \mathrm{~km}^{2}$ ) was selected for the proposed studies due to As contamination of the environment at the hazardous levels.

\subsection{Sampling of Soil and Rice Samples}

The sampling network for collection of field water, soil and rice is presented in Figure 1. The water samples were collected as prescribed in the literatures [22]. Twenty water samples (once in a month) in duplicate from August-November, 2012 were taken from 20 different rice fields. A total of 4 samples, from each field from the
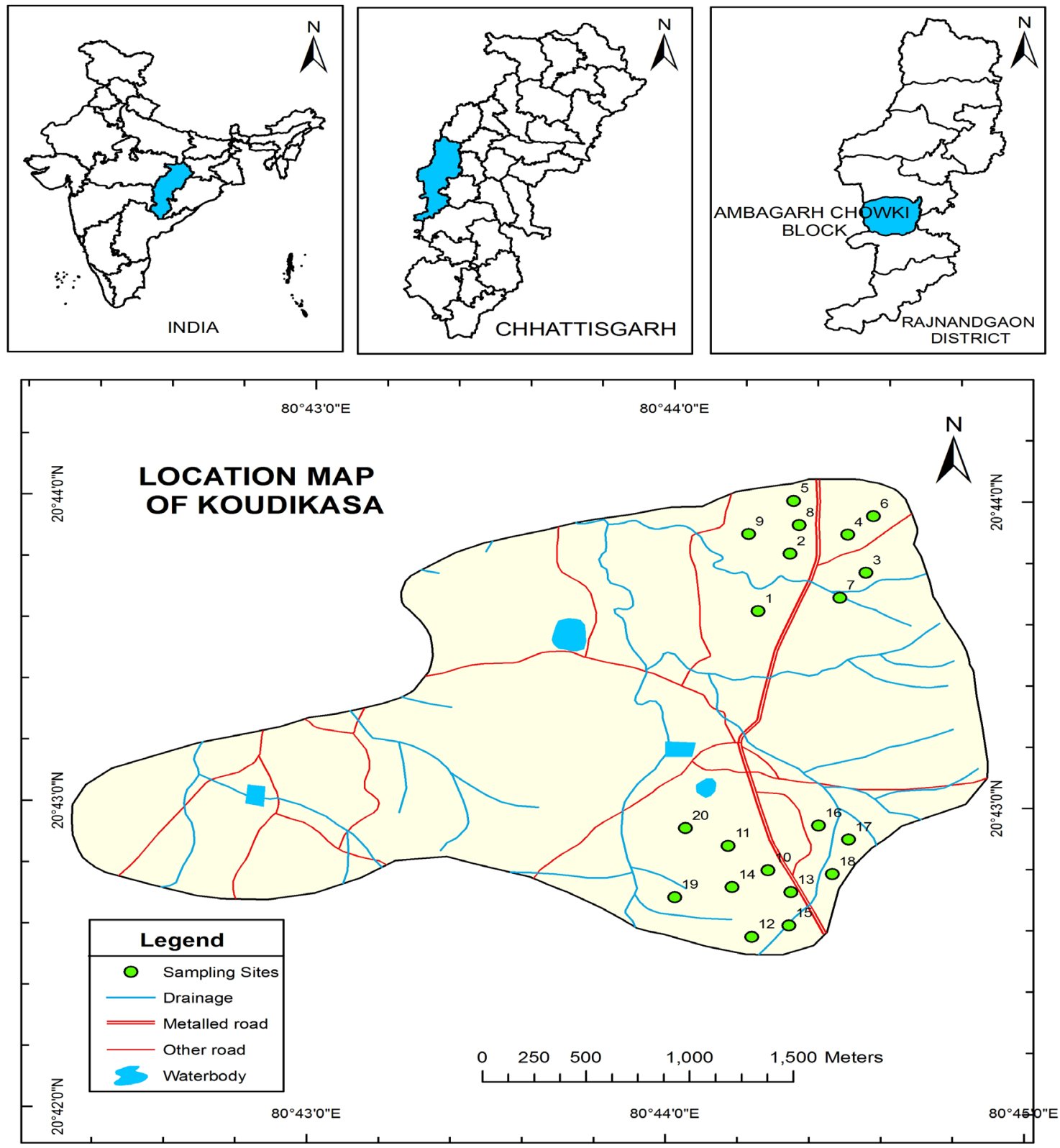

Figure 1. Sampling net-work for collection of the field soil and rice samples in Koudikasa village. 
period: August-November, 2012 was taken for the investigation. They were collected directly from rice field in duplicate, and placed in 250-mL polypropylene plastic bottle. Bottles were first rinsed thrice with the water and then, completely filled with the same water. The first sample was acidified with concentrated nitric acid $(0.1 \%$, $\mathrm{v} / \mathrm{v}$ ) for analysis of the As. The second sample was left free for analysis of the ions. The physical parameters i.e. $\mathrm{pH}$ and electrical conductivity (EC) of the water were measured at the spot.

Twenty composite soil samples (0 - 10-cm depth) were collected after harvesting of rice paddy (December, 2009) from 20 fields of Koudikasa village as prescribed in the literature [23]. The samples were stored in polyethylene bottles and dried in open air under diffused sunlight followed by drying in oven at $50^{\circ} \mathrm{C}$ for $24 \mathrm{hr}$. Rice grains were separated from the plants by hand picking in December, 2012 from the field in the polyethylene bag. They were dried in the oven at $50^{\circ} \mathrm{C}$ for $24 \mathrm{hr}$ and their husk was separated manually. Similarly, the straw and root of the rice plant were collected. They were washed with the deionized water several times to remove the soil particles. The dried soil, rice grain, husk, straw and root samples were ground to a fine powder with mortar and passed through a mesh sieve of $<1 \mathrm{~mm}$.

\subsection{Analysis}

The Bruker S2 Picofox TXRF portable spectrometer was used for the analysis of the elements in soil. A suspended solution was prepared by mixing $10 \mathrm{mg}$ of soil sample with $10 \mathrm{ml}$ of a water solution containing $1 \%$ (w/v) triton and $10 \mu \mathrm{g} / \mathrm{mL}$ Ga in ultrasonic bath for $15 \mathrm{~min}$. For each measurement, $10 \mu \mathrm{L}$ of sample solution was sprayed on the quartz filter with subsequent drying. The X-ray source was focused on the filter for quantification of the elements. The peak area of the signal was computed. The three replicate measurements for each sample were carried out. The content of 14 elements (i.e. P, K, Ca, As, Ti, V, Cr, Mn, Fe, Ni, Cu, Zn and Pb) in each soil was analyzed. The standard soil sample (NCS DC 73382 CRM) was used for the quality control.

The As content in the soil and rice samples were analysed by the ICP-MS and AFS techniques. The samples were digested with nitric acid and $\mathrm{H}_{2} \mathrm{O}_{2}$ in Perkin-Elmer microwave system. The total, inorganic and organic As species in the rice grain samples were quantified by using method proposed by Williams et al. [24]. The Rice flour SRM 1568 was used for the quality control.

\section{Results and Discussion}

\subsection{Rice Morphology}

The details of the rice morphology (i.e. cultivation period, height of plant, grain and husk content) are summarized in Table 1. The cultivation period, plant height and yield of rice varies by variety and environmental conditions, ranging from 80 - 145 day, $90-140 \mathrm{~cm}$ and 33 - 57 Q/ha with mean value of 124 day, $110 \mathrm{~cm}$ and 44 $\mathrm{Q} / \mathrm{ha}$, respectively. Among them, the plant height was found to be partially correlated $(\mathrm{r}=0.42)$ with the cultivation period. The single grain weight, rice and husk content were varied from 14 - $30 \mathrm{mg}, 65 \%$ - 87\% and 13\% $35 \%$ with mean value of $21 \mathrm{mg}, 74 \%$ and $26 \%$, respectively.

\subsection{Characteristics of Field Water}

The mean value $(n=4)$ of the water parameters in 20 fields is summarized in Table 2 . The $\mathrm{pH}$ value of the water was found to be neutral, ranging from 6.9 - 7.6 with mean value of $7.3 \pm 0.1$. The moderate EC values of the water were observed, ranging from $180-472 \mu \mathrm{S} / \mathrm{cm}$ with mean value of $316 \pm 34 \mu \mathrm{S} / \mathrm{cm}$. The concentration of $\mathrm{F}^{-}, \mathrm{Cl}^{-}, \mathrm{SO}_{4}^{2-}, \mathrm{NO}_{3}^{-}, \mathrm{Na}^{+}, \mathrm{K}^{+}$and As was ranged from 1.7 - 3.4, 10 - 43, 32 - 150, 1.9 - 7.9, 14 - 50, 2.6 - 9.8 and $0.029-0.090 \mathrm{mg} / \mathrm{L}$ with mean value of $2.4 \pm 0.2,20 \pm 4,78 \pm 12,4.2 \pm 0.7,32 \pm 7,5.2 \pm 0.8$ and $0.058 \pm$ $0.007 \mathrm{mg} / \mathrm{L}$, respectively. Among them, $\mathrm{SO}_{4}^{2-}$ showed the highest content in the water. The concentration of $\mathrm{F}^{-}$and As was found to higher than the recommended value of 1.5 and $0.001 \mathrm{mg} / \mathrm{L}$, respectively [25].

\subsection{Concentration of As and Other Elements in Soils}

The distribution of As and other elements i.e. $\mathrm{P}, \mathrm{K}, \mathrm{Ca}, \mathrm{Cr}, \mathrm{Mn}, \mathrm{Fe}, \mathrm{Ni}, \mathrm{Cu}, \mathrm{Zn}$ and $\mathrm{Pb}$ in the field soil is shown in Table 3. The concentration of elements i.e. As, $\mathrm{P}, \mathrm{K}, \mathrm{Ca}, \mathrm{Cr}, \mathrm{Mn}, \mathrm{Fe}, \mathrm{Ni}, \mathrm{Cu}, \mathrm{Zn}$ and $\mathrm{Pb}$ in the field soil $(\mathrm{n}=$ 20) was ranged from 44 - 270, 823 - 2653, 29,182 - 76,242, 12,173 - 116,031, 574 - 1306, 1623 - 14,419, 57,111 - 157,542, $245-548,237-441,444-817$ and $9-79 \mathrm{mg} / \mathrm{kg}$ with mean value of $126 \pm 28,1516 \pm 195,45192 \pm$ 5305, $35292 \pm 12135,883 \pm$ 73, $8395 \pm 1587,94804 \pm 10650,392 \pm 39,343 \pm 26,582 \pm 50$ and $32 \pm 10 \mathrm{mg} / \mathrm{kg}$, 
Table 1. Rice morphology in Koudikasa village.

\begin{tabular}{ccccccccc}
\hline S. No. & Type & $\begin{array}{c}\text { Cultivation } \\
\text { Period, day }\end{array}$ & $\begin{array}{c}\text { Height of rice } \\
\text { plant, cm }\end{array}$ & $\begin{array}{c}\text { Yield } \\
\text { Q/Ha }\end{array}$ & Grain type & $\begin{array}{c}\text { Weight of } \\
\text { grain, mg }\end{array}$ & $\begin{array}{c}\text { Rice } \\
\%\end{array}$ & $\begin{array}{c}\text { Husk } \\
\%\end{array}$ \\
\hline 1 & IR-64 & 100 & 90 & 43 & LS & 22.6 & 78 & 22 \\
2 & Culture & 80 & 110 & 43 & MS & 14.5 & 72 & 28 \\
3 & Shyamla & 130 & 90 & 33 & LS & 25.0 & 76 & 24 \\
4 & G. Gurmatia & 140 & 140 & 37 & LB & 29.6 & 81 & 19 \\
5 & Masuri & 145 & 120 & 47 & MS & 14.3 & 87 & 13 \\
6 & Purnima & 100 & 90 & 37 & LS & 21.6 & 79 & 21 \\
7 & Mahamaya & 125 & 110 & 57 & LB & 28.8 & 83 & 17 \\
8 & Kalinga & 100 & 120 & 37 & LS & 17.1 & 82 & 18 \\
9 & Luchai & 145 & 120 & 42 & MS & 13.6 & 75 & 25 \\
10 & Safari & 140 & 140 & 47 & MS & 16.3 & 72 & 28 \\
11 & Ek Hazar Das & 115 & 98 & 50 & LS & 26.0 & 70 & 30 \\
12 & Sarna & 140 & 110 & 50 & MS & 22.0 & 65 & 35 \\
13 & HMT & 130 & 110 & 43 & LS & 20.0 & 65 & 35 \\
14 & M2 & 140 & 105 & 45 & LS & 23.0 & 68 & 32 \\
15 & Zero JR & 125 & 100 & 45 & MS & 22.0 & 65 & 35 \\
16 & Sonan & 130 & 100 & 43 & LS & 24.0 & 70 & 30 \\
\hline
\end{tabular}

LS = Long slender, LB = Long Bold, MS = Medium size.

Table 2. Characteristics of field water in Koudikasa village.

\begin{tabular}{|c|c|c|c|c|c|c|c|c|c|}
\hline \multirow{2}{*}{ Field no. } & \multirow{2}{*}{$\mathrm{pH}$} & EC & $\mathrm{F}^{-}$ & $\mathrm{Cl}^{-}$ & $\mathrm{SO}_{4}^{2-}$ & $\mathrm{NO}_{3}^{-}$ & $\mathrm{Na}$ & K & As \\
\hline & & $\mu \mathrm{S} / \mathrm{cm}$ & \multicolumn{7}{|c|}{$\mathrm{mg} / \mathrm{L}$} \\
\hline Fi1 & 7.3 & 382 & 2.1 & 19 & 150 & 5.2 & 40 & 5.2 & 60 \\
\hline Fi2 & 7.4 & 180 & 2.7 & 25 & 85 & 3.4 & 17 & 3.9 & 53 \\
\hline Fi3 & 7.1 & 310 & 1.9 & 10 & 56 & 3.5 & 23 & 3.2 & 48 \\
\hline Fi4 & 7.3 & 221 & 2.0 & 12 & 32 & 4.3 & 40 & 6.5 & 65 \\
\hline Fi5 & 7.4 & 312 & 1.8 & 13 & 47 & 3.8 & 50 & 8.2 & 49 \\
\hline Fi6 & 7.1 & 229 & 2.7 & 31 & 72 & 7.2 & 14 & 2.6 & 29 \\
\hline Fi7 & 7.5 & 325 & 3.2 & 24 & 76 & 2.8 & 31 & 4.7 & 56 \\
\hline Fi8 & 7.2 & 310 & 3.4 & 43 & 92 & 1.9 & 21 & 4.3 & 90 \\
\hline Fi9 & 7.1 & 305 & 1.8 & 11 & 103 & 2.8 & 23 & 3.4 & 49 \\
\hline Fi10 & 7.2 & 439 & 2.3 & 18 & 105 & 5.7 & 34 & 6.2 & 88 \\
\hline Fi11 & 6.9 & 207 & 2.9 & 25 & 101 & 3.7 & 29 & 4.7 & 68 \\
\hline Fi12 & 7.2 & 472 & 2.1 & 10 & 69 & 3.9 & 24 & 3.8 & 62 \\
\hline Fi13 & 7.4 & 254 & 1.8 & 12 & 37 & 4.7 & 45 & 7.8 & 64 \\
\hline Fi14 & 7.5 & 374 & 1.7 & 13 & 59 & 4.2 & 46 & 9.8 & 63 \\
\hline Fi15 & 7.3 & 248 & 2.6 & 30 & 103 & 7.9 & 26 & 3.1 & 76 \\
\hline Fi16 & 7.1 & 389 & 2.5 & 24 & 83 & 3.1 & 35 & 5.6 & 49 \\
\hline Fi17 & 7.5 & 372 & 2.9 & 42 & 44 & 2.1 & 24 & 5.2 & 54 \\
\hline Fi18 & 7.6 & 351 & 2.0 & 10 & 71 & 3.1 & 25 & 4.1 & 34 \\
\hline Fi19 & 7.4 & 311 & 2.8 & 14 & 89 & 4.6 & 31 & 4.7 & 62 \\
\hline Fi20 & 7.2 & 319 & 2.2 & 17 & 92 & 5.2 & 38 & 7.7 & 41 \\
\hline
\end{tabular}

$\mathrm{Fi}=$ Field. 
Table 3. Chemical characteristics of field soil in Koudikasa village, mg/kg.

\begin{tabular}{|c|c|c|c|c|c|c|c|c|c|c|c|}
\hline S. No. & As & $\mathrm{P}$ & K & $\mathrm{Ca}$ & $\mathrm{Cr}$ & $\mathrm{Mn}$ & $\mathrm{Fe}$ & $\mathrm{Ni}$ & $\mathrm{Cu}$ & $\mathrm{Zn}$ & $\mathrm{Pb}$ \\
\hline 1 & 148 & 1528 & 42,773 & 40,453 & 878 & 12,065 & 100,476 & 413 & 437 & 648 & 64 \\
\hline 2 & 110 & 1425 & 36,673 & 38,177 & 811 & 14,292 & 104,938 & 436 & 418 & 606 & 79 \\
\hline 3 & 90 & 1761 & 46,996 & 54,885 & 838 & 10,286 & 98,347 & 410 & 357 & 584 & 62 \\
\hline 4 & 122 & 1560 & 35,543 & 37,082 & 922 & 9280 & 98,261 & 398 & 379 & 488 & 21 \\
\hline 5 & 132 & 2113 & 49,238 & 97,179 & 961 & 11,212 & 157,542 & 475 & 441 & 817 & 64 \\
\hline 6 & 44 & 1368 & 29,182 & 15,357 & 882 & 8077 & 90,405 & 320 & 279 & 455 & 46 \\
\hline 7 & 186 & 914 & 60,933 & 15,381 & 673 & 3560 & 71,388 & 245 & 314 & 533 & 10 \\
\hline 8 & 270 & 1133 & 76,242 & 13,477 & 963 & 1673 & 69,027 & 401 & 310 & 601 & 21 \\
\hline 9 & 112 & 2653 & 56,127 & 116,031 & 1099 & 10,472 & 140,329 & 495 & 425 & 768 & 66 \\
\hline 10 & 250 & 1235 & 65,635 & 12,173 & 879 & 2509 & 57,111 & 278 & 255 & 536 & 9 \\
\hline 11 & 140 & 1219 & 51,707 & 12,236 & 717 & 3846 & 68,913 & 262 & 335 & 561 & 16 \\
\hline 12 & 104 & 1318 & 48,651 & 14,209 & 640 & 5226 & 68,909 & 301 & 283 & 470 & 16 \\
\hline 13 & 110 & 1268 & 41,638 & 53,294 & 782 & 14,419 & 95,301 & 466 & 377 & 526 & 46 \\
\hline 14 & 104 & 1939 & 42,435 & 35,031 & 947 & 7287 & 87,998 & 355 & 300 & 491 & 10 \\
\hline 15 & 234 & 1173 & 35,658 & 27,387 & 574 & 7925 & 72,626 & 256 & 237 & 444 & 20 \\
\hline 16 & 70 & 1389 & 32,930 & 20,603 & 986 & 9676 & 107,638 & 425 & 365 & 547 & 28 \\
\hline 17 & 74 & 1877 & 33,457 & 22,435 & 1306 & 11,632 & 111,356 & 497 & 359 & 768 & 25 \\
\hline 18 & 56 & 1534 & 34,941 & 23,668 & 948 & 7722 & 96,383 & 548 & 283 & 526 & 12 \\
\hline 19 & 91 & 823 & 42,334 & 31,345 & 836 & 8201 & 95,473 & 411 & 363 & 514 & 11 \\
\hline 20 & 78 & 2093 & 40,740 & 25,427 & 1014 & 8534 & 103,649 & 439 & 341 & 761 & 14 \\
\hline
\end{tabular}

respectively. Among them, the highest concentration of Fe was observed in all soil samples. They were found to occur in the following increasing order: $\mathrm{Pb}<\mathrm{As}<\mathrm{Cu}<\mathrm{Ni}<\mathrm{Zn}<\mathrm{Cr}<\mathrm{P}<\mathrm{Mn}<<\mathrm{Ca}<\mathrm{K}<\mathrm{Fe}$. Among them, a good correlation $(r=0.73)$ of the As with the $\mathrm{K}$ was observed, indicating their existence as $\mathrm{K}_{3} \mathrm{AsO}_{4}$ in the soil, Table 4. The Fe showed good correlation with the heavy metals i.e. $\mathrm{Cr}, \mathrm{Mn}, \mathrm{Ni}, \mathrm{Cu}$ and $\mathrm{Pb}$ in the soil, indicating origin from similar sources, Table 4. The As concentration in the soil of studied area was found to be higher than reported in other regions of the country and World [5]-[12].

\subsection{Distribution of As in Rice Grain, Husk, Straw and Root}

The distribution of As in rice grain, husk, straw and root is summarized in Table 5. The concentration of As in the rice grain, husk, straw and root $(\mathrm{n}=20)$ was ranged from $0.17-0.72,0.40-1.58,2.5-5.9$ and $204-354 \mathrm{mg} / \mathrm{kg}$ with mean value of $0.47 \pm 0.07,0.83 \pm 0.15,4.2 \pm 0.5$ and $276 \pm 21 \mathrm{mg} / \mathrm{kg}$, respectively. The As content in husk was found to be higher than the rice grain, may be due to external contamination from the environment. The high yield rice varieties i.e. Kalinga, IR-64, G. Gurmatia, Shyamla, Ek Hazar Das, M2, etc. were found to be more sensitive to the As-accumulation. The concentration of As in the rice of the studied area was found to be higher than reported in the other region of the country and World [13]-[19]. The As content in the straw and root was found to be comparable to the values reported in the Taiwanese rice plants [14].

\subsection{Biological Absorption Coefficient and Concentration Factor}

The biological absorption coefficient, BAC (i.e. plant to soil metal ratio) and concentration factor, CF (i.e. plant to water soluble metal ratio) of As are presented in Table 6. The CF and BAC values depend on the physical 
Table 4. Correlation matrix for elements in field soil.

\begin{tabular}{|c|c|c|c|c|c|c|c|c|c|c|c|}
\hline & $\mathrm{P}$ & K & $\mathrm{Ca}$ & $\mathrm{Cr}$ & $\mathrm{Mn}$ & $\mathrm{Fe}$ & $\mathrm{Ni}$ & $\mathrm{Cu}$ & $\mathrm{Zn}$ & As & $\mathrm{Pb}$ \\
\hline $\mathrm{P}$ & 1.00 & & & & & & & & & & \\
\hline $\mathrm{K}$ & -0.12 & 1.00 & & & & & & & & & \\
\hline $\mathrm{Ca}$ & 0.71 & 0.04 & 1.00 & & & & & & & & \\
\hline $\mathrm{Mn}$ & 0.41 & -0.64 & 0.54 & 0.28 & 1.00 & & & & & & \\
\hline $\mathrm{Fe}$ & 0.73 & -0.30 & 0.82 & 0.57 & 0.69 & 1.00 & & & & & \\
\hline $\mathrm{Ni}$ & 0.55 & -0.28 & 0.51 & 0.70 & 0.64 & 0.74 & 1.00 & & & & \\
\hline $\mathrm{Cu}$ & 0.44 & -0.09 & 0.68 & 0.37 & 0.69 & 0.77 & 0.58 & 1.00 & & & \\
\hline $\mathrm{Zn}$ & 0.70 & 0.15 & 0.57 & 0.66 & 0.34 & 0.72 & 0.58 & 0.64 & 1.00 & & \\
\hline As & -0.36 & 0.73 & -0.14 & -0.35 & -0.54 & -0.48 & -0.50 & -0.29 & -0.12 & 1.00 & \\
\hline $\mathrm{Pb}$ & 0.42 & -0.14 & 0.67 & 0.13 & 0.71 & 0.63 & 0.40 & 0.71 & 0.43 & -0.19 & 1.00 \\
\hline
\end{tabular}

Table 5. Distribution of As in various parts of rice in Koudikasa village, mg/kg.

\begin{tabular}{|c|c|c|c|c|c|}
\hline S. No. & Rice type & Grain & Husk & Straw & Root \\
\hline 1 & IR-64 & 0.46 & 1.13 & 5.4 & 354 \\
\hline 2 & Culture & 0.25 & 0.40 & 2.8 & 204 \\
\hline 3 & Shymla & 0.56 & 0.84 & 4.1 & 282 \\
\hline 4 & G.Gurmatia & 0.62 & 1.11 & 5.2 & 306 \\
\hline 5 & Kalinga & 0.68 & 1.58 & 5.9 & 348 \\
\hline 6 & Masuri & 0.35 & 0.55 & 3.1 & 222 \\
\hline 7 & Purnima & 0.27 & 0.47 & 2.8 & 216 \\
\hline 8 & IR-64 & 0.62 & 1.29 & 5.6 & 318 \\
\hline 9 & Ek Hazar Das & 0.72 & 0.94 & 4.6 & 282 \\
\hline 10 & Culture & 0.48 & 0.76 & 3.8 & 258 \\
\hline 11 & Luchai & 0.50 & 1.36 & 5.7 & 330 \\
\hline 12 & Safari & 0.17 & 0.46 & 2.5 & 210 \\
\hline 13 & Mahamaya & 0.38 & 0.51 & 3.2 & 246 \\
\hline 14 & Sarna & 0.51 & 0.72 & 4.7 & 276 \\
\hline 15 & HMT & 0.48 & 0.68 & 3.8 & 258 \\
\hline 16 & M2 & 0.64 & 1.02 & 5.1 & 294 \\
\hline 17 & HMT & 0.32 & 0.51 & 2.8 & 240 \\
\hline 18 & Masuri & 0.22 & 0.44 & 2.7 & 234 \\
\hline 19 & Zero JR & 0.62 & 0.98 & 4.9 & 330 \\
\hline 20 & Sonan & 0.57 & 0.83 & 4.4 & 312 \\
\hline
\end{tabular}


Table 6. BAC and CF value of rice grain, husk, straw and root.

\begin{tabular}{|c|c|c|c|c|c|c|c|c|c|}
\hline \multirow{2}{*}{ S. No. } & \multirow{2}{*}{ Rice } & \multicolumn{4}{|c|}{ CF } & \multicolumn{4}{|c|}{ BAC } \\
\hline & & Grain & Husk & Straw & Root & Grain & Husk & Straw & Root \\
\hline 1 & IR-64 & 8 & 19 & 90 & 5898 & 0.003 & 0.008 & 0.036 & 2.4 \\
\hline 2 & Culture & 5 & 8 & 53 & 3852 & 0.002 & 0.004 & 0.025 & 1.9 \\
\hline 3 & Shymla & 12 & 18 & 85 & 5874 & 0.006 & 0.009 & 0.046 & 3.1 \\
\hline 4 & G.Gurmatia & 10 & 17 & 80 & 4710 & 0.005 & 0.009 & 0.043 & 2.5 \\
\hline 5 & Kalinga & 14 & 32 & 120 & 7104 & 0.005 & 0.012 & 0.045 & 2.6 \\
\hline 6 & Masuri & 12 & 19 & 107 & 7656 & 0.008 & 0.013 & 0.070 & 5.0 \\
\hline 7 & Purnima & 5 & 8 & 50 & 3858 & 0.001 & 0.003 & 0.015 & 1.2 \\
\hline 8 & IR-64 & 7 & 14 & 62 & 3534 & 0.002 & 0.005 & 0.021 & 1.2 \\
\hline 9 & Ek Hazar Das & 15 & 19 & 94 & 5754 & 0.006 & 0.008 & 0.041 & 2.5 \\
\hline 10 & Culture & 5 & 9 & 43 & 2934 & 0.002 & 0.003 & 0.015 & 1.0 \\
\hline 11 & Luchai & 7 & 20 & 84 & 4854 & 0.004 & 0.010 & 0.041 & 2.4 \\
\hline 12 & Safari & 3 & 7 & 40 & 3390 & 0.002 & 0.004 & 0.024 & 2.0 \\
\hline 13 & Mahamaya & 6 & 8 & 50 & 3846 & 0.003 & 0.005 & 0.029 & 2.2 \\
\hline 14 & Sarna & 8 & 11 & 75 & 4380 & 0.005 & 0.007 & 0.045 & 2.7 \\
\hline 15 & HMT & 6 & 9 & 50 & 3396 & 0.002 & 0.003 & 0.016 & 1.1 \\
\hline 16 & M2 & 13 & 21 & 104 & 6000 & 0.009 & 0.015 & 0.073 & 4.2 \\
\hline 17 & HMT & 6 & 9 & 52 & 4446 & 0.004 & 0.007 & 0.038 & 3.2 \\
\hline 18 & Masuri & 6 & 13 & 79 & 6882 & 0.004 & 0.008 & 0.048 & 4.2 \\
\hline 19 & Zero JR & 10 & 16 & 79 & 5322 & 0.007 & 0.011 & 0.054 & 3.6 \\
\hline 20 & Sonan & 14 & 20 & 107 & 7608 & 0.007 & 0.011 & 0.056 & 4.0 \\
\hline
\end{tabular}

and chemical composition of the field water, type of rice species and their morphology. The CF values in the rice grain, husk, straw and root was ranged from $3-15,7-32,40-120$ and $2934-7656$ with mean value $9 \pm 2$, $15 \pm 3,75 \pm 11$ and $5065 \pm 1646$, respectively. Relatively very low BAC values for the rice grain, husk, straw and root were observed, ranging from $0.001-0.009,0.003-0.015,0.015-0.073$ and $1.0-5.0$ with mean value of $0.004 \pm 0.001,0.008 \pm 0.002,0.039 \pm 0.007$ and $2.7 \pm 0.5$, respectively. The remarkably higher FC and BAC values with new rice variety i.e. Kalinga, Masuri, Ek Hazar Das and M2 were seen, may be due to smaller grain size and higher cultivation period, Figure 2 and Figure 3. In addition, the FC and BAC values for different plant parts were found to be fairly correlated $(r=0.76-0.96)$. The As was found to be poorly translocated from the root to grain and its concentration was found to increase in order: grain $<$ husk $<$ straw $<<$ root. The As content was found $1.9 \pm 0.3,9 \pm 1$ and $108 \pm 15$ folds higher in the rice husk, straw and root with respect to the respective grain. The higher As content in the husk, straw and root of the rice species i.e. Masuri, IR-64, Luchai, Safari and HMT was observed.

\subsection{Speciation of As in Rice}

The As species concentration in four new fast growing rice grains is summarized in Table 7. The main As species detected in the rice extract were monomethylarsenonate (MMA) and dimethylarsinite (DMA) and As(III). Total arsenic concentration of the four rice samples was varied from $207-548 \mu \mathrm{g} / \mathrm{kg}$. The inorganic As(III) concentration was ranged from $46 \%-66 \%$. The higher DMA fraction was observed in the rice grain containing higher As content. Amongst them, the lowest concentration of the MMA was marked. The inorganic and organic 


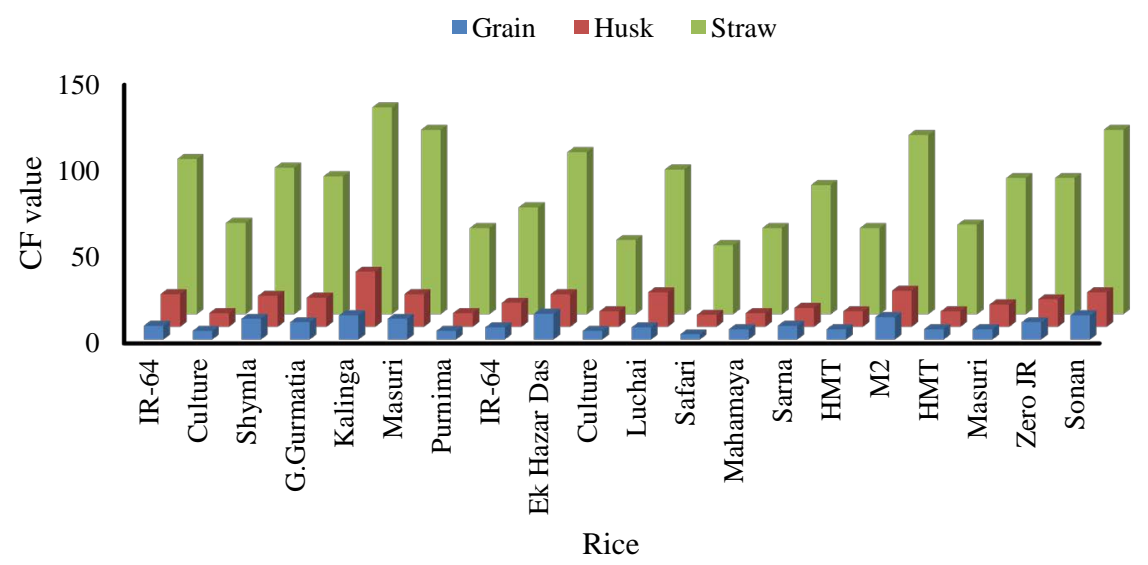

(a)

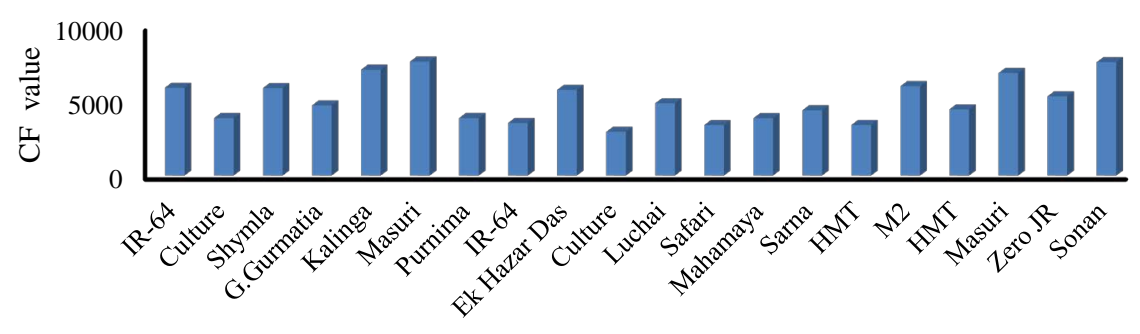

Rice root

(b)

Figure 2. The FC value of rice plants in Koudikasa village.

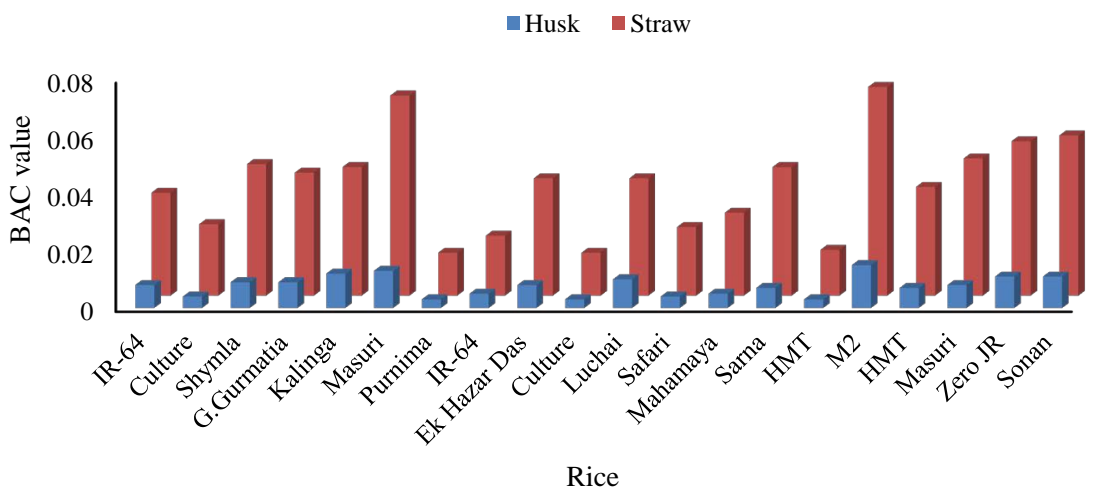

(a)

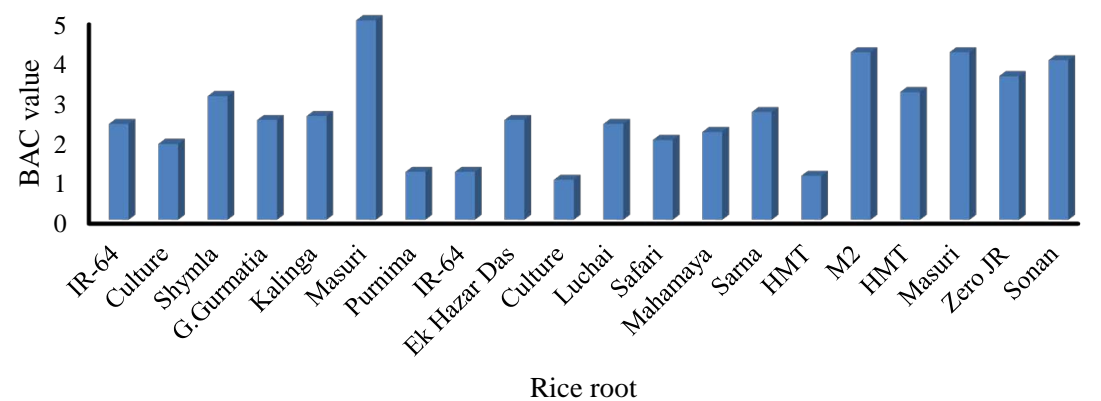

(b)

Figure 3. The BAC value of rice plants in Koudikasa village. 
Table 7. Arsenic speciation in rice grain, $\mu \mathrm{g} / \mathrm{kg}$.

\begin{tabular}{ccccc}
\hline S. No. & Sample & AsT & DMA & MMA \\
\hline 1 & CMR rice & $296 \pm 21$ & $165 \pm 3$ & $10 \pm 1$ \\
2 & Masuri & $207 \pm 39$ & 65 & 207 \\
3 & Sonan & $548 \pm 14$ & 207 & 16 \\
4 & HMT & $309 \pm 34$ & 92 & 5 \\
5 & Zero JR & $509 \pm 29$ & $95 \pm 3$ & $15 \pm 5$ \\
\hline
\end{tabular}

Certified value of As in the CMR $=290 \pm 30 \mu \mathrm{g} / \mathrm{kg}$.

As content was found to be fairly correlated with the AsT content in the grain. The distribution pattern of Asspecies in the rice grain of this region is observed similar to Bangladeshi rice [24].

\section{Conclusion}

The field water and soil were found to be contaminated with As at dangerous levels, may be due to geogenic origins. The high yield rice variety i.e. IR-64, Kalinga, Ek Hazar Das, M2, Zero JR, etc. was found to be more sensitive to the As accumulation. Several folds higher As contamination of the straw and root of the rice plants than the grain was marked. The feeding of straw to the domestic animals seems to be a potential pathway entry of As. The rice root was marked as hyper phytoextractants for accumulating As from the surface soil.

\section{Acknowledgements}

We are thankful to the Alexander von Humboldt Foundation for award of fellowship to KSP. The sincere thanks is extended to Prof. J. Feldmann, College of Physical Sciences-Chemistry, Trace Element Speciation Laboratory Aberdeen, Scotland for As speciation studies of the rice grain.

\section{References}

[1] Naujokas, M.F., Anderson, B., Ahsan, H., Aposhian, H.V., Graziano, J.H., Thompson, C. and Suk, W.A. (2013) The Broad Scope of Health Effects from Chronic Arsenic Exposure: Update on a Worldwide Public Health Problem. Environmental Health Perspectives, 121, 295-302. http://dx.doi.org/10.1289/ehp.1205875

[2] Sohn, E. (2014) Contamination: The Toxic Side of Rice. Nature, 514, S62-S63. http://dx.doi.org/10.1038/514s62a

[3] Meharg, A.A. (2004) Arsenic in Rice-Understanding a New Disaster for South-East Asia. Trends in Plant Science, 9, 415-417.

[4] Zhu, Y.G., Williams, P.N. and Meharg, A.A. (2008) Exposure to Inorganic Arsenic from Rice: A Global Health Issue? Environmental Pollution, 154, 169-171. http://dx.doi.org/10.1016/j.envpol.2008.03.015

[5] Meharg, A.A. and Rahman, M.M. (2003) Arsenic Contamination of Bangladesh Paddy Field Soils: Implications for Rice Contribution to Arsenic Consumption. Environmental Science and Technology, 37, 229-234. http://dx.doi.org/10.1021/es0259842

[6] Brammer, H. (2009) Mitigation of Arsenic Contamination in Irrigated Paddy Soils in South and South-East Asia. Environment International, 35, 856-863. http://dx.doi.org/10.1016/j.envint.2009.02.008

[7] Dittmar, J., Voegelin, A., Roberts, L.C., Hug, S.J., Saha, G.C., Ali, M.A., Badruzzaman, A.B. and Kretzschmar, R. (2007) Spatial Distribution and Temporal Variability of Arsenic in Irrigated Rice Fields in Bangladesh. 2. Paddy Soil. Environmental Science and Technology, 41, 5967-5972. http://dx.doi.org/10.1021/es0702972

[8] Stroud, J.L., Norton, G.J., Islam, M.R., Dasgupta, T., White, R.P., Price, A.H., Meharg, A.A., McGrath, S.P. and Zhao, F.J. (2011) The Dynamics of Arsenic in Four Paddy Fields in the Bengal Delta. Environmental Pollution, 159, 947-953. http://dx.doi.org/10.1016/j.envpol.2010.12.016

[9] Seyfferth, A.L., McCurdy, S., Schaefer, M.V. and Fendorf, S. (2014) Arsenic Concentrations in Paddy Soil and Rice and Health Implications for Major Rice-Growing Regions of Cambodia. Environmental Science and Technology, 48, 4699-4706. http://dx.doi.org/10.1021/es405016t

[10] Dahal, B.M., Fuerhacker, M., Mentler, A., Karki, K.B., Shrestha, R.R. and Blum, W.E. (2008) Arsenic Contamination of Soils and Agricultural Plants through Irrigation Water in Nepal. Environmental Pollution, 155, 157-163. 
http://dx.doi.org/10.1016/j.envpol.2007.10.024

[11] Smith, E., Smith, J., Smith, L., Biswas, T., Correll, R. and Naidu, R. (2003) Arsenic in Australian Environment: An Overview. Journal of Environmental Science and Health: Part A-Toxic/Hazardous Substances \& Environmental Engineering, 38, 223-239. http://dx.doi.org/10.1081/ESE-120016891

[12] Liao, X.Y., Chen, T.B., Xie, H. and Liu, Y.R. (2005) Soil As Contamination and Its Risk Assessment in Areas near the Industrial Districts of Chenzhou City, Southern China. Environment International, 31, 791-798. http://dx.doi.org/10.1016/j.envint.2005.05.030

[13] Bhattacharya, P., Samal, A.C., Majumdar, J. and Santra, S.C. (2010) Accumulation of Arsenic and Its Distribution in Rice Plant (Oryza sativa L.) in Gangetic West Bengal, India. Paddy and Water Environment, 8, 63-70. http://dx.doi.org/10.1007/s10333-009-0180-z

[14] Lin, S.C., Chang, T.K., Huang, W.D., Lur, H.S. and Shyu, G.S. (2015) Accumulation of Arsenic in Rice Plant: A Study of An Arsenic-Contaminated site in Taiwan. Paddy and Water Environment, 13, 11-18. http://dx.doi.org/10.1007/s10333-013-0401-3

[15] Rahman, M.A., Hasegawa, H., Mahfuzur Rahman, M., Nazrul Islam, M., Miah, M.A.M. and Tasmin, M.A. (2007) Arsenic Accumulation in Rice (Oryza sativa L.) Varieties of Bangladesh: A Glass House Study. Water, Air, and Soil Pollution, 185, 53-61. http://dx.doi.org/10.1007/s11270-007-9425-X

[16] Jayasumana, C., Paranagama, P., Fonseka, S., Amarasinghe, M., Gunatilake, S. and Siribaddana, S. (2015) Presence of Arsenic in Sri Lankan Rice. International Journal of Food Contamination, 2, 1. http://dx.doi.org/10.1186/s40550-015-0007-1

[17] Azizur Rahman, M. and Hasegawa, H. (2011) High Levels of Inorganic Arsenic in Rice in Areas Where ArsenicContaminated Water Is Used for Irrigation and Cooking. Science of the Total Environment, 409, 4645-4655. http://dx.doi.org/10.1016/j.scitotenv.2011.07.068

[18] Sommella, A., Deacon, C., Norton, G., Pigna, M., Violante, A. and Meharg, A.A. (2013) Total Arsenic, Inorganic Arsenic, and Other Elements Concentrations in Italian Rice Grain Varies with Origin and type. Environmental Pollution, 181, 38-43. http://dx.doi.org/10.1016/j.envpol.2013.05.045

[19] Adomako, E.E., Williams, P.N., Deacon, C. and Meharg, A.A. (2011) Inorganic Arsenic and Trace Elements in Ghanaian Grain Staples. Environmental Pollution, 159, 2435-2442. http://dx.doi.org/10.1016/j.envpol.2011.06.031

[20] Patel, K.S., Shrivas, K., Brandt, R., Jakubowski, N., Corns, W. and Hoffmann, P. (2005) Arsenic Contamination in Water, Soil, Sediment and Rice of Central India. Environmental Geochemistry and Health, 27, 131-145. http://dx.doi.org/10.1007/s10653-005-0120-9

[21] Sahu, B.L., Ramteke, S., Rajhans, K.P., Patel, K.S., Wysocka, I. and Jaron, I. (2016) Contamination of Pond with Fluoride and Heavy Metals in Central India. Water Resources, Submitted.

[22] APHA (2005) Standard Methods for the Examination of Water and Wastewater. 21st Edition, APHA, AWWA and WEF, Washington DC.

[23] Tan, K.H. (2005) Soil Sampling, Preparation and Analysis. 2nd Edition, CRC Press, Boca Raton.

[24] Williams, P.N., Price, A.H., Raab, A., Hossain, S.A., Feldmann, J. and Meharg, A.A. (2005) Variation in Arsenic Speciation and Concentration in Paddy Rice Related to Dietary Exposure. Environmental Science and Technology, 39, 5531-5540. http://dx.doi.org/10.1021/es0502324

[25] WHO (2011) Guidelines for Drinking-Water Quality. 4th Edition, World Health Organization, Geneva. http://www.haceclick.com.uy/documentos/GuIa_OMS\%202011_4aEd.pdf 